\title{
Assessment of relationship between biometric characteristics of stone and crown morphotype of Prunus Pumila L.
}

\author{
Mikhail Lezin ${ }^{1 *}$, and Larisa Ufimtseva ${ }^{2}$ \\ ${ }^{1}$ Central Siberian Botanical Garden, 630090 Novosibirsk, Russia \\ ${ }^{2}$ Ural Federal Agrarian Scientific Research Centre, Ural Branch of the RAS, 620142 Ekaterinburg, Russia
}

\begin{abstract}
Prunus pumila is an introductory species with a disjunctive culturing area, which is caused by the instability of plants to rotting on waterlogged soils with unstable winters and high snow cover. One of the varieties of Prunus pumila in natural habitats grows on acidic soils and sometimes in wetlands. In the introduction population of the Chelyabinsk region, not all varieties could take part in the formation of the introduction population. In terms of stone shape and plant habit, no specimens matching the description of the P. pumila var. depressa variety could be identified. On the basis of the classification of plant morphotypes developed by us it was possible in some cases to obtain significant differences in the distribution of stone indices in groups with different types of crowns. The maximum differences were found in groups with the crown type of raised shrub and tree shrub for the index length / width and length / thickness of the stone. In the first case, a significant difference was obtained at the $1 \%$ significance level $\left(\mathrm{t}_{\mathrm{f}}=2.81\right)$, and in the second - even at the $0.1 \%$ significance level $\left(\mathrm{t}_{\mathrm{f}}=3.78\right)$.
\end{abstract}

\section{Introduction}

For plants that have real or potential economic usefulness, it is important to identify the adaptive potential for expanding the cultivated area. For this, it is necessary to conduct research in ecological morphology and find out the adaptive values of biomorphological characters to a particular factor or a complex of factors [1]. Prunus pumila $\mathrm{L}$. is an introductory species with a disjunctive culturing area, which is caused by the instability of plants to rotting on waterlogged soils with unstable winters and high snow cover. Under natural conditions on the territory of North America, the species is represented by four varieties, differing in ecological conditions of growth and certain morphological characteristics [2-6]. One variety of $P$. pumila var. Susquehanae (Willd.) M. Jaeger, which grows on acidic and often waterlogged soils, may be of interest for obtaining cultivated forms of Prunus pumila that are resistant to dampness $[4,5]$.

The study of the introduction population on the territory of the Chelyabinsk region by a complex of diagnostic morphological characters revealed that not all varieties took the same part in the formation of the introduction population [7,8]. Thus, based on the shape of the stone and plant habit, it was not possible to reveal the participation of the P. pumila var.depressa

\footnotetext{
* Corresponding author: lezin-misha@mail.ru
} 
(Pursh) Bean variety in the introduction population in the Chelyabinsk region. With a more thorough study of these features, it was possible in some cases to obtain a reliable dependence of the stone elongation indices on the shape of the crown. The study of the shape or habit of the crown is one of the sections of the study of ecological morphology and is of theoretical and practical importance [1].

\section{Methods}

The set of field and laboratory research methods, which made it possible to obtain representative data for their further analysis, was used in the work. Morphotypes of plant habit were identified and described by us on the basis of the classical concept of the relationship between the placement of structures of plant shoot systems in space and time [9]. The study of plant morphotype variability was carried out on a random sample of 197 plants of the same age. Indexes I and II were used to characterize the relative sizes and partly the shape of the stones $[10,11]$. Index I (length / width) shows the variability of the shape of the stones from flattened $(<1.0)$ to elongated (> 1.4). Index II (width / thickness) characterizes the degree of flattening (> $1.5)$ or swelling $(<1.4)$ of the sides of the stone.

\section{Results}

Based on the study of seedlings, we have identified the following morphotypes shown in the figure 1 . The most common is raised stlanets, accounting for $71.1 \%$ of the sample. $14.7 \%$ of the plants had a crown in the form of widely spreading shrub. The rest of the groups were less than or approximately equal to $5 \%$ of the studied sample. By the shape of the stone, the most common are the round and ellipsoidal shapes of the stone (Fig. 2).

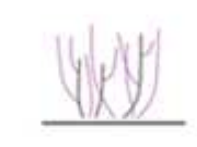

A

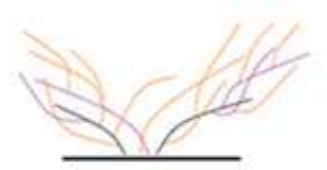

$\mathrm{D}$

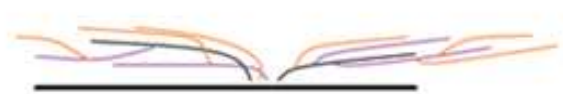

B

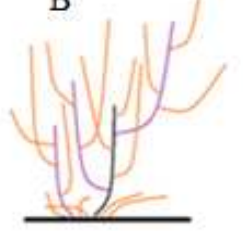

E

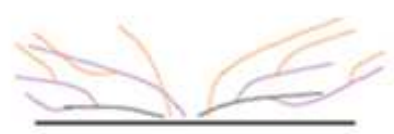

$\mathrm{C}$

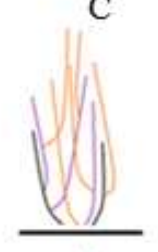

F

Fig. 1 The main morphotypes of shrub, isolated by us from P. pumila. $A$-dwarf, $B$ - stlanets, $C$ - raised stlanets, $D$ - broadly spreading shrub, $E$ - tree shrub, $F$ - pyramidal shrub. Note: $\equiv$ - shoots of different ages. 


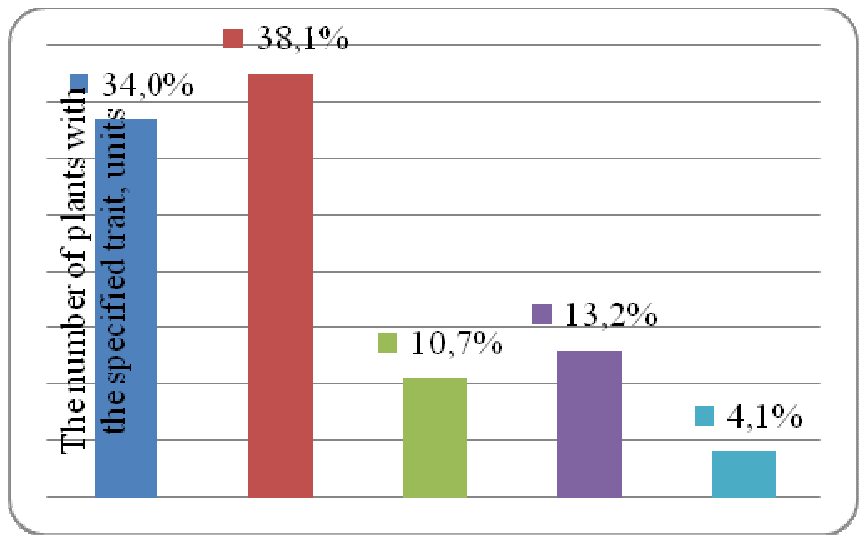

Fig. 2. The occurrence of various forms of $P$. pumila stone. 1 - rounded; 2 - elliptical; 3 - elongated; 4 ovoid; 5 - obovate.

Table 1. Variability of some biometric parameters of $P$. pumila stones.

\begin{tabular}{|c|c|c|c|c|c|}
\hline № & Indicator & $\mathrm{M} \pm \mathrm{m}$ & $\mathrm{Max}$ & Min & $\mathrm{V}, \%$ \\
\hline 1 & Stone mass, $\mathrm{g}$ & $0,25 \pm 0,01$ & 0,48 & 0,11 & 19,9 \\
\hline 3 & Stone length, mm & $9,5 \pm 0,06$ & 11,9 & 7,4 & 8,3 \\
\hline 4 & Stone width, mm & $7,1 \pm 0,03$ & 9,1 & 6,0 & 6,5 \\
\hline 5 & Stone thickness, mm & $6,4 \pm 0,03$ & 8,0 & 5,0 & 7,7 \\
\hline 6 & Length /width & $1,3 \pm 0,01$ & 1,6 & 1,1 & 7,8 \\
\hline 7 & Length / thickness & $1,5 \pm 0,01$ & 1,9 & 1,1 & 9,6 \\
\hline 8 & Width / thickness & $1,1 \pm 0,01$ & 1,3 & 1,0 & 4,3 \\
\hline
\end{tabular}

Indicators of variability of biometric data of stones of the introduction population are shown in Table 1. The level of variability of stone mass is average $(\mathrm{CV}=19.9 \%)$. For biometric indicators of stone size, the coefficients of variation correspond to a low level of variability $(\mathrm{CV}$ $=8.3-6.5 \%$ ).

Comparison of the indices of the ratio of length to width of the stone and, in addition, the width to the thickness of the stone for different types of crown is given in Table 2.

Table 2. Criterion for the reliability of differences in samples of biometric traits and habitus of P. pumila plants.

\begin{tabular}{|c|c|c|c|c|c|c|c|c|c|c|c|}
\hline \multirow{2}{*}{$\begin{array}{c}\text { Crown } \\
\text { shape } *\end{array}$} & \multicolumn{2}{|c|}{$\mathrm{D}$} & \multicolumn{2}{c|}{ Stl } & \multicolumn{2}{c|}{ R-stl } & \multicolumn{2}{c|}{ S-shrub } & \multicolumn{2}{c|}{ T-shrub } \\
\cline { 2 - 10 } & $t_{\phi}$ & $t_{\mathrm{st}}$ & $t_{\phi}$ & $t_{\mathrm{st}}$ & $t_{\phi}$ & $t_{\mathrm{st}}$ & $t_{\phi}$ & $t_{\mathrm{st}}$ & $t_{\phi}$ & $t_{\mathrm{st}}$ \\
\hline & \multicolumn{7}{|c|}{ Length /width } & & \\
\hline Stl & 0,32 & 2,16 & & & & & & & & \\
\hline R-stl & 2,07 & 1,96 & 0,50 & 1,96 & & & & & & \\
\hline S-Shrub & 1,16 & 2,04 & 0,49 & 2,02 & 0,17 & 1,96 & & & & \\
\hline
\end{tabular}




\begin{tabular}{|c|c|c|c|c|c|c|c|c|c|c|}
\hline T-shrub & 0,18 & 2,18 & 1,28 & 2,09 & 2,81 & 1,96 & 1,54 & 2,02 & & \\
\hline P-shrub & 0,65 & 2,57 & 0,39 & 2,18 & 0,23 & 1,96 & 0,20 & 2,04 & 0,98 & 2,20 \\
\hline & \multicolumn{7}{|c|}{ Length / thickness } \\
\hline Stl & 0,34 & 2,16 & & & & & & & & \\
\hline R-stl & 2,17 & 1,96 & 0,53 & 1,96 & & & & & & \\
\hline S-Shrub & 1,19 & 2,04 & 0,44 & 2,02 & 0,07 & 1,96 & & & & \\
\hline T-shrub & 0,42 & 2,18 & 1,83 & 2,09 & 3,78 & 1,96 & 2,09 & 2,02 & & \\
\hline P-shrub & 1,09 & 2,57 & 0,81 & 2,18 & 0,62 & 1,96 & 0,64 & 2,04 & 1,80 & 2,20 \\
\hline
\end{tabular}

Note: D - dwarf; Stl - stlanets; R-stl - raised stlanets; S-Shrub - broadly spreading shrub; T-shrub - tree shrub; P-shrub - pyramidal shrub

According to the results of estimation the t-criterion, it was found that the indices of linear features of the stone in groups with different types of crown significantly differ at the 5\% significance level. At the same time between crown-type groups raised stlanets and tree shrub, a significant difference was obtained for the length /width index at the $1 \%$ significance level $\left(\mathrm{t}_{\mathrm{f}}=\right.$ 2.81 ), and for the length /thickness index even at the $0.1 \%$ level significance $\left(t_{f}=3.78\right)$.

\section{Conclusion}

The significant differences in the indices of linear stone traits obtained in some combinations at the $5 \%$ significance level confirm the validity of using this classification of the crown type.

\section{References}

1. N. P. Savinykh, Siberian Journal of Ecology, 22, 5 (2015)

2. H. A. Gleason, A. Cronquist, Manual of the Vascular Plants of Northeastern United States and Adjacent Canada (Bronx, New York, 1991)

3. B. D. Mowrey, D. J. Werner, Theoretical and Applied Genetics, 80, 1 (1990).

4. P. M. Catling, S. M. McKay-Kuja, G. Mitrow, Taxon 48(3) (1999)

5. J. R. Rohrer, The Michigan Botanist, 39, 4 (2000)

6. Flora of North America, Vol. 9 (Oxford University Press on Demand, 2016)

7. M. S. Lezin, N. V. Glaz, Plant Diversity: Status, Trends, Conservation Concept, 20 (2020)

8. M. S. Lezin, V. S. Simagin, A. V. Lokteva, Proceedings on applied botany, genetics and breeding, 180, 3 (2019).

9. I. G. Serebryakov, Ecological morphology of plants (Moscow, Graduate School, 1962)

10. M. Khloptseva, Proceedings on applied botany, genetics and breeding, 104 (1986)

11. Program and methodology for the variety study of fruit, berry and nut crops (Orel, VNIISPK, 1999) 